\title{
Nós que aqui estamos por vós esperamos: a desejada aproximação entre educação básica e pesquisadores em ensino de ciências
}

\section{Those who are here are expecting for you: the desired approximation between elementary school and science education researchers}

\author{
Maylta Brandão dos Anjos* \\ Marcus Vinicius Pereira ${ }^{* *}$ \\ Giselle Rôças ${ }^{* * *}$
}

\section{Resumo}

Inspirados no documentário Nós que aqui estamos por vós esperamos, observamos como são pensadas as estratégias e maneiras de aproximar professores da educação básica e pesquisadores em ensino de ciências. Dessa forma, as inquietações e os debates de três pesquisadores atuantes nessa área traçaram caminhos de diálogo e reflexão sobre a importância e a necessidade de aproximação entre a educação básica e as pesquisas realizadas no cerne dos cursos de pós-graduação stricto sensu brasileiros, assumindo o que se legitima e se sustenta como base de qualidade no ensino de ciências e de sua prática nos pontos de ação das escolas. É dado destaque a tal pauta de discussão, tendo em vista as possibilidades e limitações entre pesquisadores (orientadores e orientandos) em ensino de ciências e os fazeres educativos constituídos nas escolas, uma vez que há uma demanda crescente que requer ação empenhada para realização de pesquisas nessa área de conhecimento, pois são nas expansões das ideias e nas relações que se estabelecem que o saber cresce. Apostamos na relação pesquisa e extensão para alcançar com mais eficiência a escola básica, refletindo sobre como o sistema nacional de pós-graduação pode e deve melhorar essa interface.

Palavras-chave: Ensino de ciências. Escola básica. Formação de professores. Pesquisa e extensão. Pós-graduação stricto sensu.

\section{Abstract}

From an inspiration in the documentary Nós que aqui estamos por vós esperamos, the authors noted how are thought out strategies and ways to bring teachers of basic education and researchers into science education. In this way, the concerns and debates of three researchers working in this area outline ways of dialogue and

Recebido em 19/11/2017 - Aprovado em 20/02/2018

http://dx.doi.org/10.5335/rep.v25i2.8177

Doutora em Ciências Sociais pelo CPDA, da UFRRJ. Docente permanente do Programa de Pós-Graduação Stricto Sensu em Ensino de Ciências do Instituto Federal de Educação, Ciência e Tecnologia do Rio de Janeiro, Campus Nilópolis. E-mail: maylta.anjos@ifrj.edu.br

* Doutor em Educação em Ciências e Saúde pelo Nutes, da UFRJ. Estagiário de pós-doutorado na Faculdade de Educação da Universidade de São Paulo (FE-USP). Docente permanente do Programa de Pós-Graduação Stricto Sensu em Ensino de Ciências do Instituto Federal de Educação, Ciência e Tecnologia do Rio de Janeiro, Campus Nilópolis. E-mail: marcus.pereira@ifrj.edu.br

**** Doutora em Ecologia pelo PPGE, da UFRJ. Docente permanente do Programa de Pós-Graduação Stricto Sensu em Ensino de Ciências do Instituto Federal de Educação, Ciência e Tecnologia do Rio de Janeiro, Campus Nilópolis. E-mail: giselle.rocas@ifrj.edu.br 
reflection on the importance and necessity of an approximation between basic education and the science education researchers, assuming what we legitimize and maintain as the basis of quality in the science teaching and its practice in the schools'actions. Given the importance of this discussion, we have seen the possibilities and limitations that occur between researchers (counselors and students) in science education and the educational practices constituted in schools, given that there is a growing demand that requires committed action to carry out of researches in this area of knowledge, because it is in the expansions of ideas and relationships that are established that knowledge grows. The authors focus on the relation between research and extension in order to better achieve basic schooling, reflecting on how the national graduate system can and should improve this interface.

Keywords: Basic school. Post-graduation stricto sensu. Research and extension. Science teaching. Teacher training.

\section{Introdução}

Enquanto ensino, continuo buscando, reprocurando. Ensino porque busco, porque indaguei, porque indago e me indago. Pesquiso para constatar, constatando, intervenho, intervindo, educo e me educo. Pesquiso para conhecer o que ainda não conheço e comunicar ou anunciar a novidade (FREIRE, 1998, p. 32).

Este manuscrito integra um rol de artigos em que estão sendo discutidas e pensadas por pesquisadores do Programa de Pós-graduação em Ensino de Ciências do Instituto Federal do Rio de Janeiro (Propec-IFRJ) questões prementes que envolvem formação continuada de professores, pós-graduação stricto sensu, ensino de ciências e avaliações conduzidas pela Coordenação de Aperfeiçoamento de Pessoal de Nível Superior (Capes), buscando compreender o cenário atual, no qual a produtividade por vezes ocorre em detrimento de uma pesquisa de qualidade e contextualizada (RÔÇAS; ANJOS; PEREIRA, 2017; PEREIRA; RÔÇAS, 2018). Criticamos, mas, sobretudo, buscamos suscitar debates e apontar possibilidades para empreendermos melhorias mais efetivas na educação brasileira, aliando-nos à educação básica que tem muito para sugerir e contribuir com as pesquisas realizadas dentro dos muros das instituições de ensino superior.

Optamos como marca de identificação dessa série de artigos a incorporação de nomes de filmes ou documentários (que nos sensibilizaram) nos títulos dos trabalhos. Assim, o presente artigo, o terceiro dessa série, baseia-se no documentário Nós que aqui estamos por vós esperamos (1999), dirigido por Marcelo Masagão, que utiliza imagens do século XX para provocar uma reflexão sobre o contexto histórico, econômico e cultural mundial. Trazê-lo como inspiração, sobretudo pelo título, à luz do ensino de ciências, é um grande desafio, entretanto, um desafio que imprime ação e crescimento dialogal, que aquece debate e análise, além de nos mobilizar a pensar novos temas e variantes no âmbito do ensino de ciências que envolvam a sala de aula e a pesquisa oriunda dela e para ela. "Nós [escola] que aqui 
estamos por vós [pesquisadores]", esperamos, reforça a nossa compreensão de que a escola tem mais a contribuir para avanços, pesquisas e discussões sobre o ensino de ciências do que ser uma reprodutora/cobaia dos nossos ensaios de pesquisa. A pesquisa deve ser fruto da parceria ativa entre escola e pesquisadores (neste caso em particular, destacamos a pós-graduação stricto sensu).

Os diversos diálogos estabelecidos durante este estudo suscitaram debates e reacenderam uma vinculação própria, ao observarmos como se dá a relação entre os sujeitos envolvidos com ensino e vida em sociedade, reforçando o quanto somos produtores e herdeiros de legados por via da educação. Assumindo o gancho com o filme de Masagão, percebemos o quanto esses sujeitos que fazem a história educacional e são em vida vulneráveis à morte (alusão no filme a uma frase de um cemitério em Paraibuna) estabelecem em seu cotidiano uma constante luta para manutenção da educação básica brasileira, direito previsto em constituição que está, a cada dia, mais ameaçado, rarefeito, quase "morto". O filme nos levou a um profundo questionar sobre a vida acadêmica e escolar e, ainda que não queiramos, estamos à espera de feitos que permaneçam após a vida, perpetuando ações conquistas para o bem da humanidade. É esse fazer que marca o percurso entre nascer e morrer. Nesse ínterim, a vida em sua dinâmica rápida acontece. A ciência e a educação são chaves, talvez as mais objetivas e lógicas, que buscam abrir e explicar esse tempo que se localiza entre os espaços do antes e do depois de nossa existência e que se perpetua com os aprendizados garantidos pela escola e pela vida.

Nascida das observações que se davam em todos os campos da humanidade, a ciência foi se firmando como um paradigma explicativo e concreto do mundo. A partir da idade moderna, assumiu um caráter mais investigativo e científico, inaugurando novas formas de experimentar sensações, de provar o que não passava de elucubrações. Dos teocentrismo e geocentrismo aos antropocentrismo e heliocentrismo, novas estruturas e novas visões do universo foram ampliadas. Ampliaram-se a visão e a ação do homem na construção social. E, assim, o homem já compreendia, para além dos dogmas e doutrinas, os fenômenos apresentados na natureza. Percebia que a ciência também apresentava respostas às suas várias instituições. Caminhou-se por séculos de descobertas e novos fazeres, até culminar na ordem explicativa atual do mundo. Foi por meio das observações, demonstrações e diálogos que a ciência foi se configurando, se instituindo como a grande resposta para a maioria dos fenômenos.

Pautados nas compreensões propostas por Bachelard (2004), entendemos esse poder de conhecer e fazer ciência baseado em princípios e espírito científico, dentre os quais evocamos a dialogicidade como tema mobilizador das observações, ampliando o olhar para pensar e apresentar como podemos buscar a vinculação e as 
características desse debate sobre ciência e pesquisa em ensino de ciências a partir de uma perspectiva educativa. Defendemos que o espírito científico pode aproximar pesquisadores e sujeitos da educação básica numa concepção que rompe o tom passivo, neutro e distante do status científico nos vários níveis educativos, para um saber científico contextualizado, desmistificado, pautado nas trocas dos saberes, pois há muito o processo de ensino-aprendizado deixou de ser verticalizado, e hoje os conteúdos estão a "um Google” de distância. É, portanto, com a escola e seus sujeitos que devemos compartilhar nossos avanços, dúvidas, achados e experiências, assumindo cada vez mais o tripé pesquisa-ensino-extensão, e apostamos que os mestrados e doutorados (profissionais e acadêmicos) da área de ensino são capazes de realizar tal indissociação. Essa aposta é fruto de nossa experiência de pesquisa e trabalho de campo (ANJOS; MAIA; BOMFIM, 2013).

A aproximação com a escola a partir da associação entre pesquisa e extensão, pautada nas trocas, observações, escutas e nos diálogos, fomenta práticas acadêmico-escolares que servirão de inspirações para as pesquisas e para os possíveis retornos dessas, recompondo os contextos e fatos a partir de uma realidade mais concreta, envolvendo todos os sujeitos do processo, extrapolando a relação orientando-orientador, comum aos nossos cursos stricto sensu. Ao se organizarem numa estratégia que dê conta de uma aproximação de produção entre pares das pesquisas e do ensino, os pesquisadores ampliarão as chances de obtenção de resultados que se tornarão mais tangíveis para a disseminação das atividades de pesquisa e extensão, e nesse ponto a relação entre atividades e pesquisas caminhará no sentido de uma interação e uma conectividade mais afinada (ZEMBAL-SAUL, 2017). Esse fato não é novo, já é feito por alguns, mas ainda de forma tímida e, às vezes, com um caráter "imperialista" ou "prescritivo" por parte de alguns colegas. Afinal, recebemos os professores da rede de ensino nos programas de pós-graduação sem, muitas vezes, considerar seus pontos de vista e um retorno de seu trabalho para o ambiente escolar, alterando ou desconsiderando seus projetos, para atender à linha de pesquisa do orientador.

Na perspectiva anunciada por Alves-Mazzotti (2003) e Cachapuz (2005), essa aproximação provoca uma sintonia dos trabalhos desenvolvidos em escolas e age numa constante de melhoria da qualidade, com as pesquisas realizadas nos programas e centros apropriados, para melhor e maior compêndio de resultados. Não obstante a isso, Alves-Mazzotti (2003) dá o seguinte exemplo: uma pesquisa em que o tema são as representações sociais, a exclusão e a qualidade na pesquisa, o que nos é apropriado para trabalhar essas questões. Nesses escritos, inferimos que, ao analisar os impactos da pesquisa educacional sobre as práticas escolares, há destaque para os pontos importantes sobre esse encontro, que marca os fatores que 
representam as dificuldades ou que impedem a apropriação da produção acadêmica por professores da educação básica. Aí é localizado um dos fatores que causa o afastamento, retardando a aproximação entre duas dimensões imprescindíveis ao ensino de ciência: escola e pesquisa.

Salientamos que, dentre as representações elencadas por Alves-Mazzotti, uma pode significar o distanciamento dos propósitos colocados em cada fase ou esfera do ensino. Além da fala acerca do distanciamento dos propósitos, há que se pensar nos aspectos gerados na ordem interna vivida pelo ensino. Assim, o título Nós que aqui estamos por vós esperamos, inspirado no letreiro de um cemitério brasileiro, vem ao encontro de repensarmos como se estabelece o além muros entre as diferentes esferas do ensino, buscando algo mais, para além da "morte" da escola. Destaque especial deve ser dado ao fato de que as pesquisas na área de ensino têm sido realizadas nos diversos níveis e modalidades da educação, mas, majoritariamente, nos ensinos médio e superior (NARDI, 2015; RUSSO, 2018), pois falamos de educação básica e pesquisa, campos mediados por pesquisadores e professores, os quais nem sempre têm oportunidades iguais. Afinal, espera-se num curso stricto sensu modalidade acadêmica uma dedicação ao curso superior a 20 horas semanais durante 24 meses, com disciplinas salpicadas durante a semana. Ao passo que os mestrados profissionais tendem a condensar as aulas em menos turnos durante a semana, mas com uma duração de até 36 meses, exigindo a permanência do mestrando no campo de trabalho/pesquisa. Entretanto, devemos estar atentos ao fato de quem tem menos flexibilidade para montar a carga horária são professores da educação infantil e do primeiro segmento do ensino fundamental (em geral, regentes únicos das turmas), diferentemente do quebra-cabeça comum ao professor do ensino médio ou do superior. Portanto, como podemos traçar as perspectivas desse encontro na pesquisa, se há realidades tão díspares? A alusão ao filme nos aponta os feitos da vida que marcaram a história nas mais singulares ações, com alternativas distintas para problemas diversos. E faz-se numa dinamicidade e numa constância da vida.

Ao não seguir uma ordem cronológica de acontecimentos, o filme coloca luz nos feitos, assim como deveriam ser nossas ações no campo da pesquisa e do ensino. Os feitos são as maiores narrativas do tempo, e, ao transpor para a educação, por ser processual, a capacidade dialética é uma constante de ação e ordenação de um pensamento que paira e reflete estratégias, relação e qualidade de aprendizado no ensino de ciências. Ao traçar a história de homens comuns, ao mesmo tempo que vai mostrando a evolução dos acontecimentos, o documentário retrata a imagem de escritores, estudiosos e cientistas em sonhos humanos, frisa o vazio do homem moderno no final do século XX, conectando-se, nesse momento, com as discussões 
que pautamos neste breve ensaio, neste diálogo que nos põe à mostra em nossas fragilidades de pesquisadores que devem se aproximar cada vez mais dos sujeitos e dos cenários de suas pesquisas - aproximando criador e criatura (Quem é cada um? Ou somos todos um pouco de cada?). Do objeto que nos torna pesquisador: a sala de aula, os sujeitos que povoam essas salas, as narrativas e os conteúdos que se fazem e constroem nesse caminho. Por isso, assim como no filme, a sala é arte de pesquisa e vida. É ação, retrato, imagem e movimento. "Nós que aqui estamos te esperamos nesta leitura" e no encontro aproximado com a docência da educação básica, porque é nas expansões das ideias que o saber cresce e as relações se fazem.

\section{Um passeio crítico em nossas ações de pesquisadores em relação às escolas}

Na perspectiva e no pensamento de aproximação entre pesquisadoras e professores da educação básica, cresce em nós a ansiedade do diálogo, que carrega a inquestionável certeza de que essa aproximação deve ser feita a todo o tempo, sobretudo nos vários níveis de atuação dos professores. São esses pontos que nos fazem crer que trazer à tona tal discussão é estabelecer uma forte tentativa de busca por uma perspectiva multidisciplinar. Estabelece-se nesse ponto um campo de análise que tem, nas metáforas de um documentário, caminho e busca para se entender a problemática histórica de como, por via das aproximações, se pode conferir maior qualidade aos trabalhos dos professores da educação básica e dos pesquisadores em ensino de ciências, sob uma propositiva de luz, de fazer consubstanciado na breve e rápida vida e no contexto permeado por ela.

Para tanto, esta reflexão tem nos professores de ciências um debate fundamental, que se traduz na relação existente, ou não, entre os pesquisadores e nos faz destacar papéis e fazeres em que estão em partilha esses desdobramentos. Partir dessa ideia nos permite destacar que os professores da educação básica, no trabalho com o ensino de ciências (e de demais disciplinas e saberes), devem levar em conta o que Fracalanza, Amaral e Gouveia (2004) afirmavam quando defendiam que o ensino de ciências deve possibilitar a compreensão das relações entre a ciência e a sociedade de forma ampla e generalizada, afirmando que os contextos devem ser pensados. Para isso, há que se observar os mecanismos de produção e apropriação dos conhecimentos científicos e tecnológicos que se dão nos espaços de ensino (FRACALANZA; AMARAL; GOUVEIA, 2004).

Vimos, nessa colocação, o quão importante são os vários elementos que aportam o nosso saber, e os filmes, em suas metáforas e metonímias, que apontam questões que trazem à ordem dos diálogos uma luz de explicação. Pensar os elos que unem pesquisa e ação em aula enriquece também a narrativa apropriada pelo 
filme que leva o título deste artigo. Refletindo sobre o documentário e sobre como a gramática apresentada por ele pode nos trazer inspiração para pensar a aproximação dos profissionais do ensino nas diversas áreas do conhecimento, observamos que é no exercício de tentar registrar e garantir a execução de práticas do ensino de ciências que a aprendizagem na educação básica se fortalece.

Interdisciplinaridade, ludicidade, tecnologias, ciência e arte e outras tantas abordagens são algumas das possibilidades presentes no cotidiano das aproximações entre professores do ensino básico e pesquisadores, respeitando o relacionamento ativo e incorporando-o à diversidade de culturas, lugares e épocas. Por isso, é importante o tema que cria identidades próximas, respeitando e reconhecendo as necessárias diferenças que se darão por via das opções que cada categoria e nível de ensino pode ter.

Assim, professores em ofício, ao falarem "nós que aqui estamos", devem dizê-lo no sentido de colaboração e de troca de uma visão integradora de suas ações, para que a pesquisa que está "por vós esperamos" crie uma relação estreita e humana, no sentido de recuperar a natureza fina de seu trabalho, e que, a partir dessa relação, a proposta de eixos de análise e estudos se constitua em passo colaborativo para todos que "esperamos". Ou seja, estabeleça-se um novo sentido, uma nova organização colaborativa e equânime entre o trabalho do professor da educação básica e dos pesquisadores de ensino de ciências, considerando que tais ações se constituam numa via de mão dupla, retroalimentando-nos e oxigenando.

A relação que se defende se pauta em áreas de diferentes níveis, permite articular saberes, apoiando-se em uma visão humanista da pesquisa e do ensino de ciências, para que possíveis fragilidades sejam superadas, e novas visões possam ser obtidas. Busca-se, então, preencher lacunas e erros na tentativa de acertos. A aproximação que se pretende tem nos anos iniciais, sobretudo no ensino de ciências, fatores que ampliam o repertório dos alunos sobre o conhecimento de objetos, seres e fenômenos naturais, para a organização e a estruturação do conhecimento posto no mundo. Nesse sentido, a prática levada às aulas deve gerar proximidade com as pesquisas, porque é das pesquisas que o ethos ação, reflexão e ação é formado. É aí que se iniciam as relações entre as práticas científicas e escolares, e essas fazem com que o conhecimento do mundo natural, obtido pelos sujeitos escolares, contribua para a formação do aluno no seu amplo aspecto de formação e entendimento do mundo.

Essa ação deve ser partilha tanto entre quem faz pesquisa no e para o ensino quanto entre quem pratica o ensino em sala, no chão da escola, nos contatos com o outro. É dessa forma que, no ensino básico, o desenvolvimento dos conceitos sobre fenômenos naturais pode se imbricar à leitura e à escrita em situações de uso que 
requerem, em linguagens diversas, formulação de ideias e noções de saberes no campo da ciência (MARQUES, 2013).

O ensino de ciências, portanto, ao ocorrer a partir da aproximação entre pesquisa e ensino, assumindo o caminho da extensão, estimulará de forma mais consentânea a curiosidade dos sujeitos alunos pela natureza científica, pelo estímulo à criação de hipóteses sobre os fenômenos naturais, provocando a imaginação e as buscas pelas explicações acerca dos fenômenos da vida. Portanto, é nessa construção dos que "aqui estão" e que por "outros esperam" que a valorização e a construção social do conhecimento ocorrerão, e encontraremos soluções e estratégias para a vida humana, promovendo a investigação, a observação, a compreensão, as relações entre os fenômenos naturais e sociais.

Nesta esteira, o professor do ensino básico verá alargada a sua prática em relação às ciências e à sua propositiva com o mundo da pesquisa. Delineará novas tendências da pesquisa escolar e acadêmica sobre o ensino de ciências, descortinando para todos os envolvidos práticas bem-sucedidas já implementadas e as angústias existentes, para que possamos alcançar conjuntamente a meta comum de melhoria da educação brasileira. Os pesquisadores e os professores numa estreita relação com a pesquisa encontrarão, no processo dessa relação, maior participação para compreender em análises os processos de investigação, assim os estudos de pós-graduação em seus níveis terão terreno maior de ação, aproximação e qualidade, para que as pesquisas signifiquem retrato, registro e transformação, e o espírito científico vivido nesses espaços seja sempre instigado, ainda que inacabado.

Para Bachelard (2004), o inacabado traduz e adjetiva o conhecimento que deve ser considerado como um postulado da epistemologia. É a esse postulado que, num modus operandis, há que se trabalhar com aproximações. Segundo o autor, o conhecimento, em sua tarefa de refinamento, precisão e busca de clareza, poderá apontar novo sentido aos conceitos de realidade e de verdade tidos pela ciência. Acreditamos ser nesse passeio que a crítica sobre nossas ações de pesquisadores no relacionamento com as escolas deve acontecer.

\section{Sujeitos ativos: professores e pesquisadores, o"nós que aqui estamos"}

A partir do título do documentário - Nós que aqui estamos por vós esperamos - e inspirados em Alves-Mazzotti (2003), podemos dizer que as metáforas estabelecem sempre uma relação com a vida imediata, demarcando um repertório de verificação do assemelhado que faz parte de uma necessidade e/ou observação que esteja mais explícita ou explicada em si. Logo, ao falar de professores e de pesquisa, apoiamo-nos também em Tardif (2007), que, com seu estudo sobre o tema, traz 
à cena um grande debate que tem, nos professores, na sua condição de sujeitos ativos, o lastro demarcado na competência de trabalhar saberes e criatividades. Segundo o autor, são esses os construtores de sua própria prática, da sua vivência e das suas experiências na sala de aula e nos vários laboratórios de pesquisa, sejam eles social ou experimental.

É esse profissional que na ordem pessoal dá luz aos novos conhecimentos, para que sejam saber instituído no campo da escola. Para tanto, é na condição de sujeitos ativos que tanto os professores quanto os pesquisadores podem dizer no mais alto tom: "nós que aqui estamos por vós esperamos". É esse "vós" que tem uma gama de cor que, tal qual um caleidoscópio, harmoniza saberes, respeitando a singeleza da essência.

Por isso, o trabalho dos professores da educação básica e dos pesquisadores que se dedicam ao campo do ensino de ciências deve ser visto como um espaço especial de produção, de construção de saberes diferenciados, de transformação e mobilização para a participação socioeducacional das realidades vividas.

Para Tardif (2007), é nesse olhar que se abrem as perspectivas para que o professor e o pesquisador se consagrem como atores do desenvolvimento de teorias e práticas que trabalham os conhecimentos e saberes gerados de suas próprias ações, de suas próprias inquietações e de seus próprios desejos. Em consonância, Lüdke $(2001,2004)$ reforça que, ao colocarmos em foco as relações da prática reflexiva, podemos desenvolver, em conjunto com as escolas básicas, a aproximação com os setores, vieses e temas de pesquisas. Porquanto, é importante, segundo Lüdke (2001), que a pesquisa seja facilitadora da prática reflexiva, que deve envolver tanto o professor quanto o pesquisador. Assinala, ainda, que, para pensar a pesquisa sob esse viés, é necessário pensar o seu desdobramento natural, reforçando o entendimento de que a prática reflexiva é passo para tornar a escola envolvida em um dos seus pilares, alimentando o olhar da curiosidade sobre o mundo e o interesse de entendê-lo já em tenra idade, para, como Bachelard (2004) já assinalou, o espírito científico começar a ser instigado.

Nesse sentido, Nóvoa (2017) assume a postura defensória de que seja firmado um compromisso que envolva escola e centros de pesquisa, bem como universidades, com a realização das pesquisas na escola. $O$ pesquisador, ao utilizar a pesquisa como um elo que aproxima academia e escola, segundo o autor, suplanta a distância criada e formada pelos preconceitos, levando ambos, pesquisadores e professores do ensino básico, a perceberem que a prática da pesquisa pode se firmar como mais um instrumento do processo educativo, que confere maior qualidade e vigor ao ensino. 
Ao se constituir numa prática elementarmente natural, a atitude cotidiana dos professores e pesquisadores rompe com a educação protocolar de cópia dos conteúdos e de memorizações desnecessárias em que a reflexão e a aplicação da prática não estejam vinculadas. Enfatiza-se a necessidade de que tanto a pesquisa quanto o ensino de ciências estejam vinculados nas diferentes esferas e níveis de formação. Compreendemos ser necessária a aproximação com Freire (1998), pois a nós parece ser uma das mais singulares inspirações, ao frisar que "não há ensino sem pesquisa, e pesquisa, sem ensino" (1998, p. 32). Seu pensamento claro nos remete à máxima "por vós esperamos". Sim, esperamos que laços mais estreitos sejam estabelecidos entre os campos da pesquisa e das práticas escolares. Esperamos que esses "fazeres se encontrem no corpo do outro", porque, segundo o autor, o que nos move é o fato de que, "enquanto ensino, continuo buscando, reprocurando. Ensino porque busco, porque indaguei, porque indago e me indago. Pesquiso para constatar, constatando intervenho, intervindo educo e me educo" (FREIRE, 1998, p. 32).

As proposições de Freire (2007) nos inspiram e apontam que a pesquisa no espaço escolar suplanta o papel de produção do conhecimento, sendo construção, formação, ação e decisão. Por ser a pesquisa processual e de formação, o autor salienta, ainda, que é por meio da interação entre a pesquisa e os professores que o saber se consolida. Destacamos os professores do ensino básico, sobretudo os que se doam às diferentes formas de viver e perceber a realidade, não se furtando da pesquisa na sua ação de transformação e do ensino na sua ação de formação. Consideramos essas duas esferas condições sine qua non para que o ensino se fortaleça, e a pesquisa se consolide como prática educativa.

Finalizando, retomamos uma vez mais Tardif, para quem

[...] um professor de profissão não é somente alguém que aplica conhecimentos produzidos por outros, não é somente um agente determinado por mecanismos sociais: é um ator no sentido forte do termo, isto é, um sujeito que assume sua prática a partir dos significados que ele mesmo lhe dá, um sujeito que possui conhecimentos e um saber-fazer provenientes de sua própria atividade e a partir dos quais ele a estrutura e a orienta (2007, p. 23).

Esse professor de profissão certamente entende a necessidade da pesquisa, e esse pesquisador de ação entende a validade da aproximação, para que essa pesquisa tenha eco, mais valor e vida.

\section{Escolha teórico-metodológica}

Os pesquisadores e professores, sobretudo na área do ensino de ciências, têm sido chamados ou instigados a rever seu papel na educação básica e na sua forma de ação em suas produções tanto em aula quanto em pesquisas. A corresponsabi- 
lidade da escola e das instituições que praticam a pesquisa reflete na baixa aproximação desses dois sujeitos que se fazem no mesmo solo e pisam a mesma terra.

Refletindo sobre esses assuntos é que nos propusemos a mergulhar numa discussão e num debate que envolvem a escola e o seu encaminhamento ou a sua aproximação com a pesquisa. Dessa forma, Nogueira (2005) assinala que novos elementos básicos são necessários para se construírem novos conhecimentos. Salienta que, nessas diferentes concepções sobre o mundo que cerca as instituições de ensino, se faz urgente a reformulação do papel do professor, e acrescentamos a essa colocação a fala do pesquisador também.

Nesse ínterim, pomos zoom em elemento que também se faz vital: rever o papel da pesquisa e dos pesquisadores acerca dessas questões. É dessa forma que nasce essa pesquisa de cunho qualitativo, que busca, nas inquietações e práticas de seus pesquisadores, um diálogo possível e um repensar das práticas acadêmicas que envolvem a pesquisa ao oferecer para os professores da educação básica uma proposta de estreita relação entre seus conhecimentos e a pesquisa científica e acadêmica. Somos orientadores de cursos de mestrado acadêmico e profissional, por isso percebemos no cotidiano de pesquisa, da orientação e da atividade de ensino (desde o ensino médio técnico até o stricto sensu) a diferença que uma prática reflexiva e debatida com os pares faz. Identificamos as diferenças entre cada uma das modalidades de mestrado e notamos o impacto dessa formação continuada no fazer diário dos professores que buscam mais essa jornada de aprendizado. As parcerias são ricas, desde que todos estejam dispostos a conhecer um pouco o lugar e o olhar do outro, encrustando-se da escuta e da vivência. O referencial teórico é fruto de nossa caminhada, de discussões, refletem nossa compreensão coletiva e nossas pesquisas, são elos comuns aos nossos trabalhos e, compreendemos, relevantes para 0 trabalho em ensino de ciências na educação básica.

A ideia estava latente, calada, esperando uma oportunidade, e, numa roda de conversas no X Encontro Nacional de Pesquisa em Educação em Ciências (2015), discutindo questões do ensino de ciências e imersos nos muitos trabalhos apresentados, fomos "atingidos" pelo título: Nós que aqui estamos por vós esperamos; a motivação inicial se deu na paráfrase que poderíamos traçar com o título de um documentário que reflete a espera ou na relação que poderíamos estabelecer entre um pesquisador e de um professor da escola básica, para que, consolidados no estreitamento dos laços que os unem à elaboração e à concretização dos caminhos de pesquisa, se pudesse conferir aos processos do ensino de ciências melhor relação e aproximação. De lá para cá, buscamos observar cada vez mais atentamente e apurar nossas escutas, e o questionamento se repete: quando escola e pesquisa 
se aproximarão? Sabemos que há aproximações, que há grupos "mergulhados” na questão, mas sabemos que essa não é a realidade majoritária. Não ainda!

Lüdke (2001) instigou-nos ao estudar as realizações que abarcam o mundo nas suas vertentes de ensino e pesquisa. Assinala que, sobremaneira, a pesquisa percorre um caminho que demarca as lacunas, que, de tão específicas, ficam evidentes quando ocorre a ausência dos diálogos entre as categorias que perfazem os professores.

A investigação voltou-se para a leitura dos autores citados e para a reflexão do campo de trabalho do professor da educação básica, buscando compreender como se dá (ou não) sua relação com os pesquisadores que atuam no ensino de ciência. Adotamos o nosso próprio campo de trabalho, por considerarmos que os contextos vividos eram instigadores e favoreciam o exercício da pesquisa na sua prática reflexiva. Assim, percebemos as muitas e possíveis atividades que estão sendo ou deveriam ser desenvolvidas com e para os professores. O professor não é o único sujeito na defesa de aproximação entre escola-pesquisa, há sujeitos ocultos: os alunos, os servidores administrativos, a gestão, os responsáveis e a comunidade. Defendemos que todos esses sujeitos devem integrar a rede de pesquisa, guardando os cuidados necessários para uma pesquisa com desenho metodológico bem elaborado. Não é envolver por envolver, mas envolver sempre que suas vozes fizerem a diferença.

Ao debruçar-nos sobre o assunto, as apropriações vividas neste processo remeteram-nos a Schön (1995), que, a exemplo de outros autores, também caros para nós, põe em evidência as aproximações entre docência e pesquisa na díade "reflexão na ação" e convoca-nos para o tripé pesquisa-ensino-extensão. Para o autor, esse processo se expressa na relação direta com o conhecimento na base de seu trabalho. Essa base foi determinante para os nossos debates e discussões. Foi nessa reflexão que pesquisa e sala de aula se imbricaram, aumentando o repertório de entendimento do mundo e de experiências mobilizadas em situações similares. Para tanto, a atitude de refletir sobre a ação docente permitiu que pensássemos o planejamento de fazeres futuros.

As reflexões de Schön nos fizeram lembrar da condição dos professores como intelectuais, como incentivadores e catalisadores de teorias que modificam cenários e explicam fenômenos. Nas análises do autor, podemos traçar um diálogo que aponte caminhos ou um paralelo que renda e resgate em nós um discurso que reconheça as necessidades atávicas de aproximação entre os professores e as pesquisas/ os pesquisadores que agem na perspectiva "nós que aqui estamos e esperamos..."

Freire (2007) defende que, ao problematizar as situações do cotidiano, criam-se as condições para que a aprendizagem transforme os educandos e educadores em sujeitos da própria aprendizagem. Ao problematizar e estabelecer o diálogo, os 
sujeitos da educação, inevitavelmente, farão reflexões que ocasionarão maior compreensão de suas contradições e da realidade em que estão imersos. É esse desvelamento da realidade que implicará a condição de enxergar mais além, com o intuito de gerar aproximações entre as dimensões de quem ensina e de quem faz pesquisa. É a partir desse ponto que se pode traçar caminhos metodológicos para superação das contradições que foram postas entre escolas, academias e centros de ciências. Por isso, a metodologia de revisão bibliográfica, com análise qualitativa das experiências vividas, apoiada nas reflexões de Freire (1998, 2007), Lüdke (2001, 2004), Alves-Mazzotti (2003), Bachelard (2004), Tardif (2007) e Schön (1995), auxiliou-nos.

\section{Resultados sem sê-los}

O objetivo deste estudo foi promover um diálogo sobre as possíveis articulação e aproximação entre professores do ensino básico e pesquisadores do ensino de ciências. Dessa forma, o que temos assinalado são algumas observações que consideramos relevantes e representativas de nossas reflexões. Assim, enfatizamos que o trabalho do professor da educação básica como situação e contexto tem merecido atenção. Schön (1995) enriqueceu esse debate ao tratar da valorização da reflexão na experiência, e é essa experiência que pode ser o fator da pesquisa que leva o professor a refletir, reflexionar e modificar sua prática, superando lacunas vivenciadas na sala de aula. Ainda conforme Schön, podemos observar que a epistemologia da prática pode dar ao pesquisador um caráter que não prescinde a análise, a produção e a criação a respeito da sua ação.

As aproximações que devem ocorrer entre professores e pesquisadores caminham num sentido muito maior, que abrange não só a produção de conhecimento a partir do cotidiano, da vivência e da experiência da sala de aula, mas, sobretudo, um campo teórico e científico, por meio da pesquisa que coloca em contato as dimensões de sujeitos que perfazem o ensino, sejam professor, aluno ou, o que consideramos como elementar nessa relação, pesquisador. É nas teorias que a estrutura do trabalho científico e escolar ganha destaque, e a metodologia se torna lastro de qualidade, para que conhecimentos acerca do ensino de vivências promovam novos saberes, novas pesquisas, e estreitem laços de memória e fazeres.

Para Schön, o controle das atividades de pesquisa pelo professor coloca os projetos de pesquisa como mais uma responsabilidade da atividade docente, situação a ser pensada. Porém, o que se discute é o plano de autonomia das pesquisas e dos pesquisadores ligados a programas de pós-graduação, de mestrado ou doutorado, ou a grupos de pesquisa vinculados às instituições de ensino e aos centros de pes- 
quisa que possa articular os conhecimentos gerados nesses ambientes e trocá-los, aquecendo o ensino nas escolas. De forma bastante positiva isso já é realidade nos colégios de aplicação das universidades; então, por que não expandimos o modelo? Essa questão nos é cara, considerando que somos professores de um instituto federal, que possui ensino médio técnico, licenciaturas e programas de pós-graduação lato e stricto sensu, mas não oportuniza essa condição de aproximação em seus próprios corredores. Esse é um espaço “desocupado" por nós, não sem proposições, mas por falta de clareza por parte de alguns gestores e da própria política pública que nos rege.

Essa discussão é importante porque leva o professor a compreender o papel do pesquisador. Esse professor buscará conferir mais qualidade à sua prática docente. Também confere ao pesquisador uma melhor compreensão do papel do professor, evitando elucubrações e proposições vazias. Entretanto, precisamos destacar que há possibilidades para que esse encontro comece a se efetivar de forma mais contundente e apontar que, ainda de forma tímida, percebemos que os estágios supervisionados realizados pelos bolsistas da Capes e as atividades de práticas de estágio supervisionado (exigência curricular para todos os mestrados profissionais da área de ensino) são alguns caminhos que podem - e devem - ser explorados de maneira mais efetiva e eficiente.

Todavia, há que pensar nos demais sujeitos, conforme já citamos, em especial, o aluno. Para apresentar alguns resultados sobre a reflexão que realizamos acerca da aproximação dos professores com a pesquisa, é imprescindível pensar o aluno que pretendemos formar. Que cidadão pretendemos ter? Que participação e que visão esperamos dos alunos que passam pelas escolas? A partir dessas indagações, inferimos que o professor, ao executar seu trabalho com ciências, deve considerar as necessidades de: contribuir para o aprendizado dos conceitos básicos das ciências naturais e a aplicação dos princípios aprendidos a situações práticas; e possibilitar a compreensão das relações entre a ciência e a sociedade e dos mecanismos de produção e apropriação dos conhecimentos científicos e tecnológicos (FRACALANZA; AMARAL; GOUVEIA, 1986). Nesse contexto, o professor do ensino básico se fortalecerá para ensinar ciências com um repertório maior e com mais acesso às chaves de compreensão dos fenômenos da natureza.

Outras questões que trazemos à tona como resultado, para que se dê a aproximação entre professores do ensino básico e pesquisares, são o trabalho e o desenvolvimento do ensino de ciências em sala de aula de maneira a contribuir com a formação nos mais diferentes aspectos, sejam eles social, cultural ou político, para que a estrutura do conhecimento básico e aplicado seja e esteja consubstanciada num potencial criativo, especulativo, explicativo e transformador e que possa ser 
apropriada e compreendida por meio do ensino e da pesquisa que se desenvolvem em parcerias entre escola e academia, tendo como mediadores e fazedores da ciência na sua ação e reflexão professores e pesquisadores.

Delizoicov, Angotti e Pernambuco (2009) destacam que o ensino de ciências, ao ser acessado nas várias dimensões, estreita as relações e aprofunda o diálogo sobre o fazer científico, devolvendo conhecimentos que aliam sala de aula ao fazer científico como atividades humanas socio-historicamente determinadas. Os autores defendem o uso e a interpretação de situações significativas que envolvam a pesquisa nas aulas, constituindo assim os temas oriundos das curiosidades levantadas, que serão relevantes ao poder de análise e funcionarão como pontos de partida e temas para pesquisas, em que as conceituações científicas estruturarão novas programações para o ensino de ciências e para a dinamicidade do processo ensino-aprendizagem. As perspectivas entre ensino e pesquisa no ensino básico e a aproximação entre quem ensina e quem faz pesquisa são correlacionadas às atividades de sala de aula, aos diálogos provocados nesse espaço, que subsidiarão não somente $\mathrm{o}$ trabalho docente, mas também as pesquisas derivadas desse trabalho e efetivadas nele.

Assinalamos mais um componente que consideramos como resultado de nossos diálogos e análises: por mais que haja uma verdade eufemizada, o título Nós que aqui estamos por vós esperamos urge em aproximar professores da educação básica e pesquisadores em ensino de ciências. Essa tentativa deverá ser realizada em todas as ordens e esferas do saber que trabalham com formação, capacitação e desenvolvimento docente. Quão próximos estão? Quão próximos estarão? Quão próximos querem ficar?

A aproximação somente poderá ser medida em resultados que se somem à qualidade da formação, à execução de práticas coadunadas com a realidade, bem como ao exercício de responsabilidade e à vivência consciente sobre os aspectos que mobilizam ciência, sociedade, educação e vida!

Por fim, para que a relação entre esses sujeitos que constroem conhecimentos mediados em diálogos e pesquisas acadêmicas e escolares esteja mais próxima, torna-se imperioso que os programas de pesquisa estejam implicados nessa proposta, investindo em linhas e projetos que atendam às demandas das escolas num vínculo estreito para suprir demandas. Dessa forma, acreditamos que abordagens que abarcam a interdisciplinaridade e a pluralidade devem ser traçadas como inerentes à prática do ensino de ciências, bem como ao processo de reflexão, ação e reflexão, conforme já nos assinalou Freire, em busca de entendimento a respeito dos diferentes aspectos que perpassam as pesquisas educativas. 
No resgate dos aspectos descritos neste trabalho e dos princípios a eles relacionados, pode-se encontrar o arcabouço para se construir pesquisas que favoreçam o trabalho de professores e pesquisadores, de todos que vivem e fazem a escola, os programas e centros de pesquisas atualmente.

São essas instituições que têm papel fundamental na vida dos sujeitos que passam por elas e têm nelas a sua formação profissional, social, cultural e cognitiva, que vão produzir nos sujeitos do ensino básico uma ação mais sensível, que se preocupe, cada vez mais, em enfrentar as novas demandas da formação.

\section{Concluindo sem concluir}

A função do professor e do pesquisador não prescinde, de forma alguma, da sala de aula, pelo contrário. Passa pela motivação da pesquisa: tudo o que cerca e perfaz a sala de aula e o que redunda dela. As aproximações que devem acontecer entre professores e pesquisadores, intermediadas pelas pesquisas e pela sala de aula, alargam a compreensão da realidade e a participação desses sujeitos no mundo, refinando a visão sobre as questões cotidianas e o olhar sensibilizador necessário a elas.

Professores e pesquisadores são produtores e construtores de saber que, ao buscarem compreender a natureza dos fenômenos, o fazem na base e na convicção de estarem empreendendo à dimensão educativa uma contribuição indelével ao aprendizado dos alunos, futuros pesquisadores e professores, sobretudo no elo de suas formações e atuações em atividades profissionais, sociais e humanas.

As possibilidades de construção de diálogos acerca da aproximação entre professores e pesquisadores constituem-se num agir comunicativo, que não nasce pronto, mas se faz em favor da educação, numa constante reconstrução de saberes que depende da díade ensino e pesquisa. Um agir que nasce para sujeitos históricos e sociais circunstanciados por um processo de aprendizagem que se socializa por via das relações que acontecem como fruto dos diálogos e observações postos em aula e laboratórios para construção desse conhecimento. Esse desafio emerge da necessidade de a ação docente e de pesquisa buscar o entendimento e o conhecimento sobre ciência como atividade humana que requer apropriação dos resultados para desenvolvimento, melhoria da vida e garantia de um devir mais consciente e harmonioso entre os sujeitos que constroem o que vivem e se constroem ao viver. Nesse modus vivendis, todos que aqui estamos por vós, que nos leem, esperamos. 


\section{Agradecimentos}

Agradecemos o apoio e o fomento dados pelo Campus Nilópolis, pela Proppi do IFRJ e pela Faperj. Agradecimento especial fazemos ao professor e colega Alexandre Maia do Bomfim e à pós-doutoranda Denise Figueira-Oliveira, que participaram de várias das discussões sobre o tema e enriqueceram o texto com sugestões, após leituras atentas e comprometidas.

\section{Referências}

ALVES-MAZZOTTI, Alda Judith. Representações sociais e exclusão: em busca da qualidade na pesquisa. In: JORNADA INTERNACIONAL SOBRE REPRESENTAÇÕES SOCIAIS, 3, 2003, Rio de Janeiro. Anais eletrônicos... Rio de Janeiro, 2003.

ANJOS, Maylta Brandão dos; MAIA, Eline Decacche; BOMFIM, Alexandre Maia do. Os desafios da construção de um Mestrado Profissional: um panorama dos sete anos do Propec. Polyphonía, Goiânia, v. 24, n. 2, p. 319-337. 2013. Disponível em: <https://www.revistas.ufg.br/sv/article/ viewFile/37941/19059>. Acesso em: 22 jan. 2018.

BACHELARD, Gaston. Ensaio sobre o conhecimento aproximado. Rio de Janeiro: Contraponto, 2004.

CACHAPUZ, António (Org.). A necessária renovação do ensino das ciências. São Paulo: Cortez, 2005.

DELIZOICOV, Demétrio; ANGOTTI, José André; PERNAMBUCO, Marta Maria. Ensino de ciências: fundamentos e métodos. 3. ed. São Paulo: Cortez, 2009.

FRACALANZA, Hilário; AMARAL, Ivan A.; GOUVEIA, Mariley S. Flória. O ensino de ciências no primeiro grau. São Paulo: Atual, 2004.

FREIRE, Paulo. Pedagogia da autonomia: saberes necessários à prática educativa. 37. ed. São Paulo: Paz e Terra, 1998.

Pedagogia do oprimido. Rio de Janeiro: Paz e Terra, 2007.

LÜDKE, Menga (Coord.). Aprendendo o caminho da pesquisa. In: FAZENDA, Ivani (Org.). Novos enfoques da pesquisa educacional. São Paulo: Cortez, 2004. p. 111-120.

. (Coord.). O professor e a pesquisa. Campinas, SP: Papirus, 2001.

MARQUES, Cristina da Silva. Narrativas e práticas investigativas na formação de professores: o ensino de ciências à luz dos fenômenos da Física. 2013. 123 f. Dissertação (Mestrado em Ensino de Ciências) $\square$ Programa de Pós-Graduação Stricto Sensu em Ensino de Ciências, Instituto Federal do Rio de Janeiro, Rio de Janeiro, 2013. Disponível em: <http://www.ifrj.edu.br/webfm_ send/5403>. Acesso em: 13 jan. 2018.

MASAGÃO, M. Nós que aqui estamos por vós esperamos. Documentário. São Paulo: Filmark Distribuidora, 1999. 
NARDI, Roberto. A pesquisa em ensino de ciências e matemática no Brasil. Ciência \& Educação, Bauru, v. 21, n. 2, p. I-V, 2015.

NOGUEIRA, Maria Alice. A relação família-escola na contemporaneidade: fenômeno social/ interrogações sociológicas. Análise Social, Lisboa, v. 11, n. 176, p. 563-578, 2005.

PEREIRA, Marcus Vinicius; RÔÇAS, Giselle. Rebobine, por favor: como avaliamos as pesquisas na área de ensino de ciências? Revista Brasileira de Ensino de Ciência e Tecnologia, Ponta Grossa, v. 11, n. 2, 2018.

RÔÇAS, Giselle; ANJOS, Maylta Brandão dos; PEREIRA, Marcus Vinicius. Quanto vale ou é por quilo: o peso da produção acadêmica na área de ensino. Ensino de Ciências e Tecnologia em Revista, Londrina, v. 1, n. 1, p. 46-66, 2017.

RUSSO, Ana Lucia Rodrigues Gama. Um panorama sobre a história e filosofia da ciência no ensino de química nas dissertações e teses (2011-2015) da área de ensino. 2018. Dissertação (Mestrado em Ensino de Ciências) $\square$ Programa de Pós-Graduação Stricto Sensu em Ensino de Ciências, Instituto Federal do Rio de Janeiro, Nilópolis, 2018.

SCHÖN, Donald. Formar professores como profissionais reflexivos. In: NÓVOA, António (Coord.). Formação de professores e profissão docente. Lisboa: Dom Quixote, 1995. p. 15-33.

TARDIF, Maurice. Saberes docentes e formação profissional. Petrópolis: Vozes, 2007.

ZEMBAL-SAUL, Carla. Minding the Research - Practice Gap: Promising Approaches for Continuous Innovation in Science Teacher Education. In: CONGRESO INTERNACIONAL SOBRE INVESTIGACIÓN EN DIDÁCTICA DE LAS CIENCIAS, 10, Sevilla. Anais... Sevilla, 2017. 